dividual licences or quotas up to the full extent of the limits set by the supply position. Bulk licences will be given to paper makers and importers authorizing them to deliver or convert any paper produced or imported by them, with certain specific exceptions, which include newsprint, insulating cable paper, certain classes of paper used for packaging, etc. The use of paper for newspapers and periodicals will still be restricted by the provisions of the Paper Control Orders. The improvement in the supply position from non-dollar sources, it is stated, has made these modifications possible, and the need to maintain waste paper salvage at the highest possible level remains as great as ever.

\section{Symposium on Animal Speciation}

A sympostr on "Ecological and Genetic Factors of Specigtion in Animals" was held by the Istituto Italiano di Idrobiologia, Pallanza (Novara), Italy, during July 29-August 2. The meeting was sponsored by the Consiglio Nazionale delle Ricerche (Italian National Research Council), whose general secretary, Dr. A. Morelli, opened the symposium, which was attended by thirty-four biologists. Papers were read by : E. Baldi, Pallanza (isolation mechanisms in populations of plankton freshwater crustaceans); M. Benazzi, Pisa (genetic-systematic studies on Triclades); F. G. Brieger, Piracicaba (heterosis in population-genetics and evolution); H. Burla, Zurich (ecology of Drosophila species of Switzerland); U. D'Ancona, Padua (Nemi's Daphniæ during twentyfive years of observations); A. Dreyfus, São Paulo (sex-ratio in hybrids and its interpretation by the study of salivary chromosomes); M. Galgano, Florence (ecological and genetic factors in the sexual cycle of amphibians); J. B. S. Haldane, London (importance of disease in evolution and speciation); J. Heuts, Louvain (ecological and genetic factors in the speciation of the fish Gasterosteus aculeatus) ; F. Mainx, Vienna (chromosomal races of the Agromyzine Lirryomiza); B. Rensch, Münster (histological transformations by change in body size) ; H. SpurwayHaldane, London (comments on Vavilov's law of homologous variation); V. Tonolli, Pallanza (isolation and stability of high-mountain Diaptomid populations); L. Trevisan, Pisa (evolution of the elephants during the Quaternary). Prof. Th. Dobzhansky, of Columbia University, New York, introduced the theme for discussion, and at the end of the meeting summed up the proceedings. The papers will be published in a special volume, edited by thp Consiglio Nazionale delle Ricerche.

\section{The Night Sky in February}

Full moon occurs on Feb. 13d. 09h. 08m., U.T.,

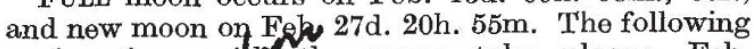
conjunctions wi the moon take place: Feb. 13d. 22. Jaturn $3^{\circ} \mathrm{S}$; ; Feb. 23d. 23h., Jupiter O.N.ME 15.25 d. 07h., Mercury $6^{\circ}$ N.; Feb. 26d. 15h., Vim $4^{\circ} \mathrm{N}$. In addition to these conjunctions with the moon, Mercury is in conjunction with Venus on Feb. 10d. 08h., Mercury $4^{\circ} \mathrm{N}$. Mercury sets less than half an hour after the sun on Feb. 1 and is in inferior conjunction on Feb. 2. At the middle of the month the planet is stationary and rises an hour before sunrise, but it is not favourably placed for observation during February. Venus is a morning star, rising at $6 \mathrm{~h} .56 \mathrm{~m}$., on Feb. 1 and 14 , and at $6 \mathrm{~h} .40 \mathrm{~m}$. towards the end of the month, but is then too close to the sun for observation. Mars is still too close to the sun for favourable observation. Jupiter rises at $6 \mathrm{~h} .35 \mathrm{~m}$. , 5h. 55m. and 5h. $08 \mathrm{~m}$. on Feb. 1, 14 and 28 , respectively, and can be seen, but not favourably, for a short time in the eastern sky. Saturn is in opposition to the sun on Feb. 21 and is visible in the constellation of Leo Major, a little east of Regulus, during the night. Occultations of stars brighter than magnitude 6 are as follow: Feb. 3d. 2lh. 13.4m., $e$ Pisc. $(D)$; Feb. 4d. 20h. 43.4m., 54 Ceti $(D)$; Feb. 15d. 22h. 47.1m., $\eta$ Virg. $(D)$; Feb. 15d. 23h. $34 \cdot 3 \mathrm{~m} ., \eta$ Virg. $(R)$. $D$ and $R$ refer to disappearance and re-appearance, respectively, and the latitude of Greenwich is assumed.

\section{Announcements}

THw Conmittee of Privy Council for Agricultural Research has appointed Prof. F. T. Brooks, who has receptly retired from the chair of botany in the Unversity of Cambridge, to be a member of the Agricultural Research Council. This is Prof. Brooks' second term of office as a member, his first being during 1941-46.

THE Swiney prize for 1949 has been awarded, on the recommendation of a joint committee of the Royal Society of Arts and the Royal College of Physicigns, to Prof. John Glaister, of the University of Glasgow, for his work "Medical Jurisprudence and Toxicology". This is the second occasion on which Prof. Glaister has received the Swiney Prize, it having been awarded jointly to him and Prof. J. C. Brash in 1939 for their book "Medico-Legal Aspects of the Ruxton Case". The Prize, which is offered alternately for medical and general jurisprudence and consists of a $£ 100$ silver cup and money to the same amount, is awarded on every fifth anniversary of Dr. George Swiney's death on January 21, 1844.

Mr. A. If Bacharach has been appointed to the staff of the Public Relations Director, Glaxo Laboratories, Ltd.; his long scientific and editorial experience will thus be available to assist all sections $f^{\prime}$ the Company's public relations organisation. Dr. W. F. J. Cuthbertson will succeed him as head of the Nutrition Unit, Research Division, of Glaxo Laboratories, Ltd.

THE date for the receipt of applications for the Nuffield Folndation Research Fellowship in Extraction Metallurgy has been put forward to March 31, 1949. The Fellowship will be tenable at the Royal School of Mines, London, for a period of up to fite years, and the funds available are sufficient to provide a salary of $£ 1,200-£ 1,500$ a year, as well as some $£ 2,500$ a year for assistants and apparatus. Applications should be sent to the Secretary, Institution of Mining and Metallurgy, Salisbury House, London, E.C.2.

REFERRIN/ to the communication "Occurrence of Acanthocephalus rance Schrank. in Great Britain" (Nature 162, 1001 ; 1948), Dr. N. B. Eales, of the University of Reading, writes: "Mr. R. Phillips Dgles has recorded the occurrence of Acanthocephalus rance from the duodenum of frogs from either Cornwall or Surrey. We have also obtained this parasite from frogs caught locally during 1948. It is therefore not improbable that the specimens at Queen Mary College came from the frogs in the neighbourhood of London."

ERratuy. In the communication "Relationship Between the Average Carcase Weight of Rams, Ewes and Lambs" (Nature, January 15, p. 100), for " $R+E=\Pi L "$, read " $R+E=\pi L "$. 